\title{
Effects of Computer-Mediated Communication (CMC) Peer Review in an EFL Writing Course
}

\author{
Yiwen $\operatorname{Lin}^{1}$ \\ ${ }^{1}$ School of English for International Business, Guangdong University of Foreign Studies, Guangzhou, China \\ Correspondence: Yiwen Lin, School of English for International Business, Guangdong University of Foreign \\ Studies, 2 Baiyun Avenue, Baiyun District, Guangzhou, China. E-mail: 1154096643@qq.com
}

Received: October 3, 2020

Accepted: November 5, $2020 \quad$ Online Published: November 13, 2020

doi:10.5539/ijel.v10n6p417

URL: https://doi.org/10.5539/ijel.v10n6p417

\begin{abstract}
This study aims to investigate the effects of the two-step blended computer mediated communication (CMC) peer review process (Word commenting followed by Zoom discussion) in an English writing course for 29 Chinese EFL learners, and their perceptions of this mode. Compared with previous studies, the findings of this study are encouraging: 1) the proportions of revision-oriented comments students gave reached at a high level of above $85 \%$ of the total comments; 2) students gave more local comments, but the ratio of revision-oriented comments in global areas to revision-oriented comments in local areas was more balanced (approximately $40 \%$ vs $60 \%)$; 3) the adoption rates of revision-oriented comments in text revision were also at a high level $(63 \%-73 \%)$. What's more, most students held positive attitudes toward this mode, perceiving it useful in their text revision and development of writing ability. $65 \%$ of them expressed their willingness to attend this mode of review activities in the future. This study reveals that the two-step CMC peer review process with Word commenting followed by discussion via online video conferencing system can be used as a useful tool in EFL writing class. This study contributes to the current research on CMC peer review since most previous studies investigated effects of peer review using text-based CMC tools and little research has been done on speech-based tools.
\end{abstract}

Keywords: peer review, computer mediated communication, EFL writing

\section{Introduction}

Peer review is considered as an indispensable part of process writing. Its potential benefits have been revealed in many scholars' researches. The major benefits include: it facilitates collaborative learning among students (Tsui \& Ng, 2000; Rollinson, 2005); it helps students to develop a sense of audience by offering opportunities for them to discover the mismatch between writer's intended meaning and reader's understood meaning (Berg, 1999; Villaim \& Guerrero, 1998; Tsui \& Ng, 2000; Rollinson, 2005); it helps to raise students' awareness of their strengths and weakness and to cultivate their self-regulatory behaviours (Villail \& Guerrero, 1998; Rollinson, 2005; Yang, Badger, \& Yu, 2006); it helps to reduce students' dependence on teacher and boost learners' autonomy (Shen, Bai, \& Xue; 2020); it helps to improve students' text revision (Mendonca \& Johnson, 1994; Villail \& Guerrero, 1998; Rollinson, 2005; Berg, 1999; Paulus, 1999; Yang et al., 2006); it helps in students' long-time writing development (Rollinson, 2005; Yang et al., 2006).

Apart from traditional face-to-face classroom peer review, computer-mediated communication (CMC) peer review has also received scholars' attention in recent years. Teachers and scholars try to incorporate new CMC tools into peer review activities and explore their effects. Some scholars adopted asynchronous communication tools such as MS Word (Ho \& Savignon, 2007), blog (Liou \& Peng, 2009; Chen, 2012; Xu \& Yu, 2018), Blackboard (Guardado \& Shi, 2007; Chang, 2012) and online forum (Pritchard \& Morrow, 2017); some scholars used synchronous tools such as instant messaging MSN (Jin \& Zhu, 2010; Chang, 2012). Some scholars (Liu \& Sadler, 2003; Yu \& Choe, 2010; Ho, 2015) adopted a two-step blended peer review procedure combining asynchronous interaction (Microsoft Word commenting) and synchronous interaction (online chat or OnlineMeeting).

The author of this study has been teaching EFL writing courses for approximately ten years. Due to the outbreak of Covid-19, all courses in the spring semester of 2020 had to be conducted online. Traditional face-to-face peer review became impossible. Therefore, I designed a two-step CMC peer review process: an electronic 
commenting mode using "insert comments" feature of Microsoft Word followed by peer discussion via online video conferencing system Zoom. This process is similar with the traditional mode the students in this study used in the previous semester in which they gave written comments on peers' printed essays and then had face-to-face discussion in classroom.

The aim of this study is to investigate the effects of the two-step CMC peer review process (Word commenting followed by Zoom discussion) in English writing courses for EFL learners, and students' perceptions of this mode. The research questions include: 1) What kinds of comment are generated in this CMC mode? 2) To what extent do student writers adopt peer comments in their subsequent revision? 3) How do students perceive the experiences and the usefulness of this mode?

\section{Literature Review}

Studies have been done on effects of CMC peer review. Some studies have revealed the positive effects: it can help students to improve text revision and writing skills (Liu \& Sadler, 2003; Guardado \& Shi, 2007; Liou \& Peng, 2009; Chang, 2012; Chen, 2012; Ho, 2015; Xu \& Yu, 2018); it can help students to improve their writing behaviours and make students more responsible for their learning (Chen, 2012); it can reduce students' anxiety and make the environment less intimidating (Liu \& Sadler, 2003; Liou \& Peng, 2009; Chen, 2012; Chang, 2012; Pritchard \& Morrow, 2017; Abdullah, Hussin, \& Shakir, 2018). Training can play an important role in achieving positive effects (Liou \& Peng, 2009; Xu \& Yu, 2018). Some studies also revealed negative effects. For instance, the use of social media MSN can distract students from tasks (Jin \& Zhu, 2010; Chang, 2012) and participants' lack of computer skills will cause tension among peers (Jin \& Zhu, 2010).

Regarding the comment quality and adoption of comments in text revision, different studies have different findings. For instance, Yu and Choe (2010) discovered that students focused primarily on types of wrong word, style, verb errors, sentence structure and content. Liu and Sadle (2003) compared the two-step traditional peer review and the two-step CMC peer review. They found that students using Word commenting produced more comments in local issues than they did when using paper-based commenting and that students' peer review talk via MOO produced more superficial comments. What's more, the adoption rate of CMC peer review was significantly less than that of traditional mode. Ho (2015) also did a similar comparative study but gained different results: the proportion of global revision-oriented comments was significantly higher than that of local revision-oriented comments in both traditional and CMC modes; the adoption rate of CMC peer review was just slightly lower than that of traditional mode.

Regarding the students' perception of CMC peer review, some studies acquired positive findings. Most students believed they improved English writing skills through CMC peer review (Chen, 2012; Xu \& Yu, 2018). Some studies revealed students' mixed feelings. For instance, Guardado and Shi (2007) found that text-based interaction scared students away from further communication and peer review via Blackboard became a one-way communication where misunderstanding arose and comments were ignored. Some comparative studies investigating students' preference also gained inconsistent results. In Liu and Sadler's (2003) study, students liked using chat room MOO and disliked using the Word editing function. But in Ho's (2015) study, the result was just the opposite. Students preferred Word commenting over handwritten comments but they preferred face-to-face discussions over online chat. Ho and Savignon (2007) as well as Pritchard and Morrow (2017) also found that the majority of participants preferred face-to-face mode over CMC mode because students considered oral discussion critical in peer review.

Research also shows that training is important both in traditional peer review or CMC peer review. Min (2005) discovered that sufficient training could help students to produce more relevant and specific comments on global issues. In a later study in 2006, Min found that after training, students incorporated significantly more peer comments in their revision and gained higher revision quality. An action research on blog-based CMC peer feedback by $\mathrm{Xu}$ and $\mathrm{Yu}(2018)$ also revealed that training enhanced students' engagement in review tasks and helped improve comment quality.

This study is similar with studies by Ho (2015), Liu and Saddle (2003). We all used a blended two-step review process and we all chose Word commenting mode in the first step. The difference lies in the second step: they used synchronous text-based tools while I chose a synchronous speech-based tool. I chose a video conference system simply because I used this system in my on-line classes, and people nowadays do not use text-based tools for synchronous communication very often. Little research has been done on the effects of speech-based CMC tools in peer review in writing classes. Thus, this study will fill this gap. 


\section{Method}

\subsection{Participants and Setting}

The participants were 29 EFL students (26 females and 3 males, aged 18-20) in one class taught by the author in the spring semester of 2020 at a university in Southern China. The students had been learning English for at least ten years. Their average score of English in College Entrance Examination was 134 (the total was 150), approximately equivalent to IELTS 7.5. Their English proficiency were estimated to be above high-intermediate level. However, because the writing task in College Entrance Examination were comparatively easy (writing a 100-word invitation letter, for example), they did not learn English academic writing in high school. All of them were freshmen majoring in International Business and were required to take the course of English Writing II, a course aiming to develop students' abilities to write expository and argumentative essays with the strategies of illustration, classification, comparison and contrast, cause and effect as well as argumentation. The course lasted 16 weeks and the teacher met the students once a week for 90 minutes. Before this course, the students had taken English Writing $I$ which aimed at paragraph writing in the previous semester and had been instructed to do traditional two-step peer review.

\subsection{The Writing Cycle and Procedure of Peer Review}

The first four weeks, the teacher gave lectures on the elements of good arguments and basic structure of English essays.

The next 12 weeks, students completed three cycles of writing in which they finished three 500-word essays with three rhetorical modes: comparison or contrast, cause and effect as well as argumentation respectively. Each cycle of writing lasted four weeks and the detailed procedure was as follows:

week 1: in class, the teacher gave lecture on how to use a specific writing strategy with model essays; then students were assigned the writing topic. After class, students finished the first draft as homework.

Week 2: in class, the teacher conducted a peer review training by explaining in detail the peer review form (adapted from Paulus, 1999) which covered five areas: contents, organization, vocabulary, language use and mechanics (see Appendix A). In area of vocabulary and language use, the vocabulary and grammar error types based on and adapted from James' (2001) classification were provided for students' reference. Then, the teacher modeled how to use this form to evaluate a sample student essay by showing, through screen sharing on Zoom, each step of making electronic comments with "insert comments" features of Word. After class, students chose their peer, exchanged their first drafts and gave their comments electronically.

Week 3: before class, the students took back their first drafts and read peer's comments carefully. In class, the teacher assigned each pair of students to separate breakout rooms on Zoom and students held discussion on comments of their first drafts. After class, based on peer's comments and their discussion, the writer revised first draft and wrote second draft. After revision, they needed to give reply to each comment. For example, if the writer agreed with a piece of comment and had made relevant revision, he/she put a " $\sqrt{ }$ " in reply to the comment; if the writer did not agree and made no revision, he/she needed to explain briefly why by "replying" the comment (an example of reviewer's comment and writer's reply is shown in Figure 1). At last, the writer wrote a reflective journal with guided questions to reflect his/her opinion about the peer review activities and the problems he/she encountered.

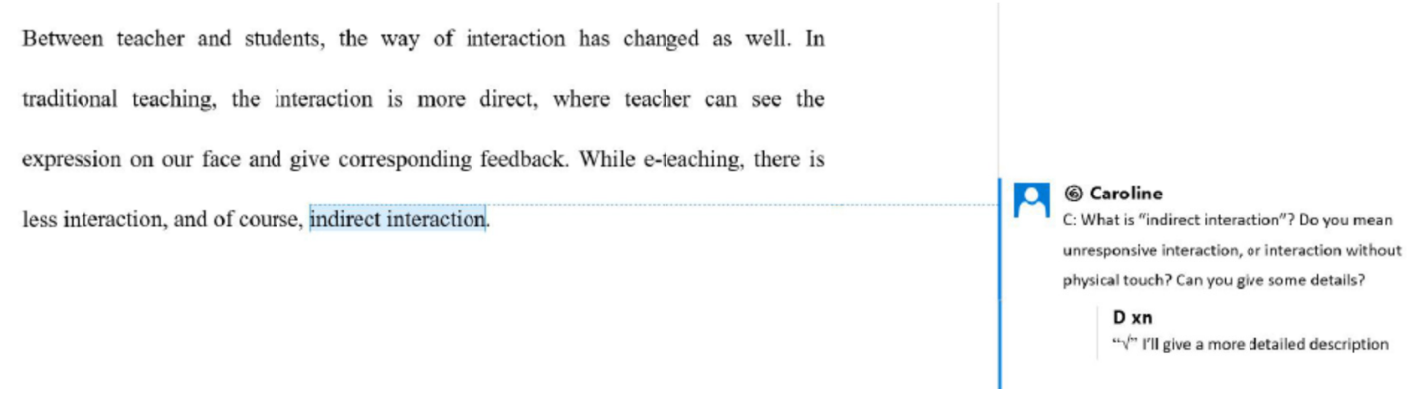

Figure 1. An example of the reviewer's comment and the writer's reply

Week 4: the teacher gave E-feedback on students' second drafts and discussed the common problems in class. 
After class, students wrote final draft.

A whole writing cycle is shown in Figure 2.

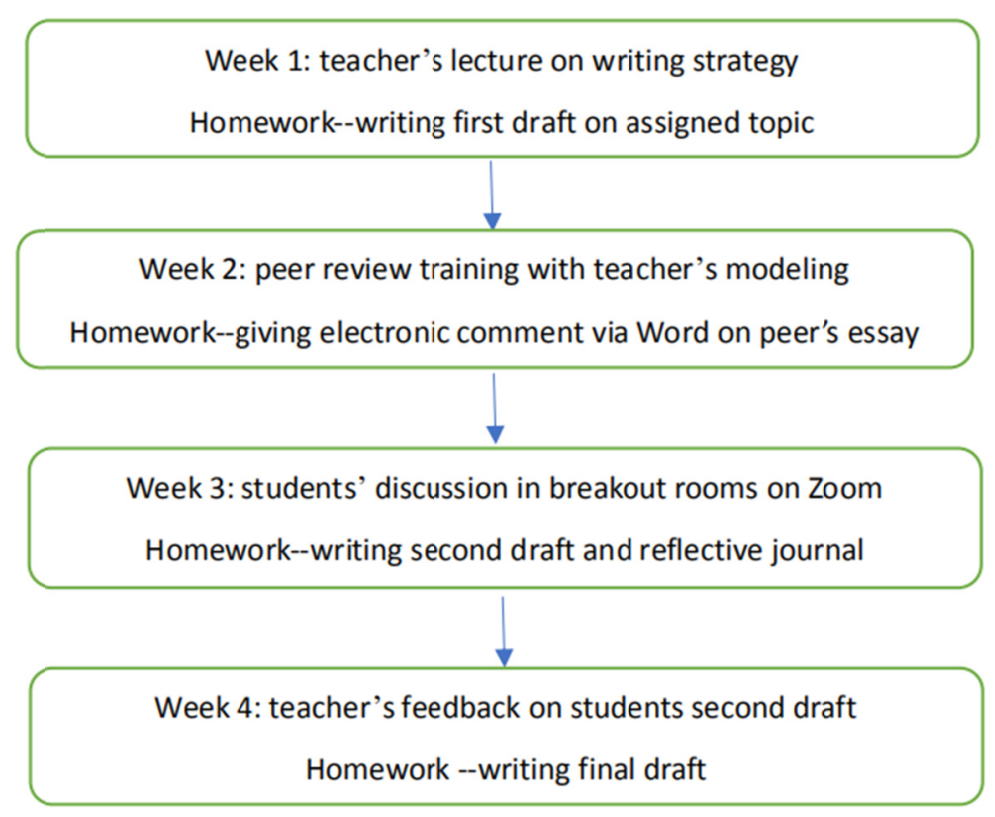

Figure 2. The writing cycle for each assignment

\subsection{The Writing Topics}

The writing topics for three assignments are:

Topic 1: E-learning and traditional face-to-face classroom learning (a comparative or contrastive essay)

Topic 2: AI technology's impact on employment (an effect essay)

Topic 3: Students choose one of the following four topics to write an argumentative essay:

No news about violent crimes?

Separate teaching for disruptive school students?

A waste for well-educated women to be housewives?

Should we revive traditional Chinese characters?

\subsection{Data Collection and Analysis}

Students submitted all drafts of three assignments and reflective journals through an online course management app-Cloud Class. At the end of the semester, students were invited to complete a questionnaire survey (adapted from Chen, 2012) asking them about their experience and opinion about this mode of peer review activities.

After data collection, the researcher made the following analysis.

Reviewer's comments and writer's replies on students' first drafts were carefully analyzed. Firstly, the total number of reviewer's comments in each cycle was counted. Secondly, based on different nature, comments were classified into revision-oriented and non-revision-oriented and the number of each nature was counted. Revision-oriented comments include suggestion, clarification, and critical evaluation while non-revision-oriented comments include chatting, and praise (Liou \& Peng, 2009). Also, comments which are too vague to understand are categorized to non-revision-oriented ones (Liu \& Sadle, 2003). Table 1 shows the classification with students' examples. Next, the revision-oriented comments were further classified into five different areas (content, organization, vocabulary, language use, and mechanics) and the number of comments in each area was counted. Lastly, writer's replies were examined. The number of revisions made by the writer based on peer comment was counted by looking for the " $~ "$ " and comparing the initial draft and the second draft to see if the actual revision took place. 
Table 1. Examples of revision-oriented comments and non-revision-oriented comments

\begin{tabular}{lll}
\hline Classification of comments by nature & Comment type & Examples from student reviewers' comments \\
\hline $\begin{array}{l}\text { Revision-oriented } \\
\text { comments }\end{array}$ & $\begin{array}{l}\text { suggestion } \\
\text { clarification }\end{array}$ & $\begin{array}{l}\text { "cost" should be "costs". } \\
\text { What is "indirect interaction"? Do you mean unresponsive interaction, } \\
\text { or interaction without physical touch? Can you give some details? }\end{array}$ \\
& critical evaluation & $\begin{array}{l}\text { This topic sentence does not support the thesis statement. And the } \\
\text { comparison pattern is not clear. }\end{array}$ \\
& praise & $\begin{array}{l}\text { These two examples are really interesting and realistic! It is meaningful } \\
\text { to mention. }\end{array}$ \\
& too vague comment & I feel a bit strange. I don't know whether it is wrong. \\
Non-revision-oriented comments & No examples for this category \\
&
\end{tabular}

When doing the counting, each insertion of comment was carefully examined. If it dealt with one problem, it was counted as one comment. If an insertion dealt with more than one problem, then it was counted as more than one comment. In some cases, the reviewer discussed just one problem, but he/she gave comments of different nature. For example, he/she gave a praise first and then pointed out the problem and/or gave a suggestion. In this case, the praise was counted as one comment independently because it is non-revision-oriented in nature and identification of problem (clarification or critical evaluation) and/or suggestion was counted as another comment because both belong to revision-oriented criteria. Below are some examples.

Example 1:

Writer's text: While in e-learning, there is less interaction, and of course, indirect interaction.

Reviewer's comment: What is "indirect interaction"? Do you mean unresponsive interaction, or interaction without physical touch? Can you give some details?

This insertion was counted as one comment in the area of content.

Example 2:

Writer's text: Thirdly, the overall job quality will be enhanced. People no longer need to do some boring and repetitive work.

Reviewer's comment: It is a little bit absolute. Try to add some limit words like "maybe" or "perhaps". Also, an explanation why this will happen is necessary, I think.

This insertion was counted as two comments as it dealt with two problems: the first concerning language use and the second concerning content.

Example 3:

Writer's text: However, in my opinion, a full-time housewife doesn't represent no time for talents. For example, J.K. Rowling, the famous author from U.K., every night before going to bed, told bedtime stories to her children, then the masterpiece HARRY POTTER came to the world. Does this stand for a waste of talent? On the contrary, it's a new value created thanks to her talent.

Reviewer's comment: Excellent example, but it is not convincing enough. What if give more examples of other prominent women in other fields?

This insertion was counted as two comments: the first half is a praise and the second half is a suggestion.

\section{Results and Discussion}

\subsection{Number and Type of Peer Comments}

\subsubsection{Total Number of Comments}

As shown in Table 2, the total number of comments made in three rounds of peer review was decreasing even though the total words of students' first drafts in three assignments did not vary much. In the first round, students made 429 comments in total. In the second round, this total number decreased to 418 . Considering that the total words of students' first drafts in the second assignment were 712 words less than those in first assignment, this decrease is reasonable. The most remarkable change, however, happened in the third round where this total number decreased dramatically to only 323 , even though the total words of first drafts in the third assignment were nearly the same with those in the first assignment. 
Table 2. Number and percentage of comments by nature

\begin{tabular}{llll}
\hline & 1st assignment & 2nd assignment & 3rd assignment \\
\hline Revision-oriented & $372(87 \%)$ & $368(88 \%)$ & $275(85 \%)$ \\
Non-revision-oriented & $57(13 \%)$ & $50(12 \%)$ & $48(15 \%)$ \\
Total comments & 429 & 418 & 323 \\
Total words of first drafts & 14614 & 13902 & 14603 \\
\hline
\end{tabular}

The possible explanation for this dramatic decrease may be students' tiredness near the end of the semester when the last round of peer review was conducted. In the first two rounds, students felt fresh about the new mode and showed high level of engagement. As time went by, however, their enthusiasm decreased because of the heavy workload. Last semester, they did peer reviews at paragraph level, so they just needed to comment on a 150 -word paragraph each time. But they needed to review an essay of 500 words in each round in this semester. This was a big increase in workload. What's more, as all courses were carried out online and all homework assignments had to be done electronically, students had to sit in front of computers for a long time. In their third reflective journal, some students expressed both physical and mental tiredness. For instance,

"After doing two peer reviews, I realized the workload was quite big and I felt tired. Both of us lost interests and patience. We gave less comments and spent less time on the task. I just wanted to finish it quickly as I had a lot of deadlines and exams for other courses."

\subsubsection{Number of Revision-Oriented Comments}

Table 2 also shows that in all three rounds, the majority (above 85\%) of the comments made by student reviewers were revision-oriented in nature. In the previous studies, Liu and Sadler's (2003) reported a higher proportion of 92\%, while both Ho (2015) as well as Liou and Peng (2009) reported a lower proportion of 60-70\% and $68.7 \%$ respectively. The proportion of this study is still relatively high, which indicates that students were efficient in commenting part.

Two reasons may explain this. Firstly, the students had done peer reviews last semester and thus they knew how to give clear and helpful comments. Second, the students followed peer review form strictly. The form used in this semester was very similar to those they used in the last semester, which underwent several revisions based on their opinions. Most students considered it as a helpful guidance in review activities.

\subsubsection{Number and Percentage of Revision-Oriented Comments by Area}

Table 3 shows that in all three rounds students gave more local revision-oriented comments than global revision-oriented comments. The revision-oriented comments in global areas (content and organization) accounted for approximately $40 \%$ of the total revision-orientated comments (with a slightly lower percentage of $37 \%$ in the second round), while the revision-oriented comments in local areas (vocabulary, language use and mechanics) accounted for approximately $60 \%$.

The results of previous studies are not consistent. In Ho's (2015) study, students made significantly more global revision-oriented comments than local ones in CMC peer reviews. But in Liu and Sadler's (2003) study, students made much more local revision-oriented comments than global ones (222 vs 69) in CMC peer reviews and the proportion of local revision-oriented comments reached as high as $76 \%$. The results of this study are similar with Liu and Sadler's but the ratio of global revision-oriented comments to local ones is more balanced. I agree with Liu and Sadler's explanation that Word commenting features help students to identify local errors, such as spelling and grammar errors. However, as the focus of my classroom teaching was development of effective argument, students also paid quite a lot of attention on content (the number of comments in content occupied the second biggest share of the total). Thus, the distribution of global revision-oriented comments and local ones is more balanced.

Table 3. Number and percentage of revision-oriented comments by area

\begin{tabular}{|c|c|c|c|c|c|c|c|}
\hline \multirow[b]{2}{*}{ Global } & \multirow[b]{2}{*}{ Content } & \multicolumn{2}{|c|}{ 1st assignment } & \multicolumn{2}{|c|}{ 2nd assignment } & \multicolumn{2}{|c|}{ 3rd assignment } \\
\hline & & $112(30 \%)$ & $40 \%$ & $105(28 \%)$ & $37 \%$ & $87(32 \%)$ & $39 \%$ \\
\hline & Organization & $37(10 \%)$ & & $31(8 \%)$ & & $21(8 \%)$ & \\
\hline \multirow{3}{*}{ Local } & Vocabulary & $136(37 \%)$ & $60 \%$ & $117(32 \%)$ & $63 \%$ & $89(32 \%)$ & $61 \%$ \\
\hline & Language use & $68(18 \%)$ & & $98(27 \%)$ & & $65(24 \%)$ & \\
\hline & Mechanics & $19(5 \%)$ & & $17(5 \%)$ & & $13(4 \%)$ & \\
\hline \multicolumn{2}{|c|}{ No. of revision-oriented comments (total) } & 372 & & 368 & & 275 & \\
\hline
\end{tabular}


Table 3 also shows the distribution of revision-oriented comments in specific areas. Student reviewers gave most revision-oriented comments in the area of vocabulary with proportions ranging from $32 \%-37 \%$. The second biggest share was in the area of content $(28 \%-32 \%)$. Then, those comments in language use and in organization came next, with proportions ranging from $18 \%-27 \%$ and $8 \%-10 \%$ respectively. Students gave least revision-oriented comments in mechanics.

These proportions did vary slightly in three rounds, which may indicate students' slight change in focus in review activities. These changes might be related to the writing assignment or teacher's focus in teaching. For instance, the first assignment was to write a comparison or contrast essay. One of the teaching focuses for this writing cycle was the comparison structure. As a result, students paid more attention in structure and organization in writing and in the later peer review activities. Thus, it is not surprising to see the proportion of revision-oriented comments in organization is the highest (10\%) among three rounds. Apart from this, students gave much more revision-oriented comments in the area of language use in the second round than in the first round ( $98 \mathrm{vs} 68$ ). This might be the result of the teacher's added language training session in the second writing cycle. When I read students' first assignments, I found that many sentences were very sweeping (e.g., E-learning has no limits of space and time) and students did not realize this problem, so I added a training on how to qualify a statement to make it not sweeping. Students paid special attention on this problem in subsequent peer review. One student wrote in her reflective journal, "in recent class, the teacher put a lot of emphasis on avoiding sweeping statement. So, when I read my partner's essay, I also pay more attention in this aspect." Therefore, the teacher's focus in class did affect students' focus in review activities.

\subsection{Adoption Rate of Revision-Oriented Comments}

\subsubsection{Overall Adoption Rate}

As shown in Table 4, the overall adoption rates of revision-oriented comments in three rounds range from $63 \%-73 \%$. These rates are encouraging compared with those reported in previous studies. The overall adoption rates in Ho's (2015) study were 69\% and 58\% in two CMC peer reviews with Word and OnlineMeeting. Liou and Peng (2009) reported a 47.7\% adoption rate in their weblog-based peer review study. Liu and Sadler (2003) reported the lowest adoption rate of only $27 \%$ in peer reviews using Word and MOO. Ho (2015) explained that the communication tools might be the reason leading to the difference in adoption rate. Ho (2015) contended that weblog lacked immediacy and timely response and MOO was less convenient than OnlineMeeting in communication in that it could not enable students to discuss problems while reading drafts on screen simultaneously as OnlineMeeting could. I agree with Ho's idea that communication tool will affect adoption. In their studies, the tools are text-based and students communicated by typing on screen, which is somehow time-and energy-consuming. But communication via Zoom is speech-based. Students can talk with faces shown while sharing documents on screen simultaneously. In their reflective journals, most students wrote that they felt no difference between Zoom discussion and the classroom discussion except some network problems. The smooth discussion via Zoom could helped students to clarify their doubts and reinforce their comments made in Word commenting part. This probably accounts for the higher adoption rate in this study.

Table 4. Percentage of peer comments leading to revision by area

\begin{tabular}{|c|c|c|c|c|c|c|}
\hline \multirow[b]{2}{*}{ 1st assignment } & \multirow{2}{*}{$\begin{array}{l}\begin{array}{l}\text { Area of } \\
\text { comments }\end{array} \\
\text { Global }\end{array}$} & \multirow{2}{*}{$\begin{array}{l}\text { No. of } \\
\text { comments } \\
198\end{array}$} & \multicolumn{2}{|c|}{$\begin{array}{l}\text { No. and } \% \text { of } \\
\text { revision-orientated comments }\end{array}$} & \multicolumn{2}{|c|}{$\begin{array}{l}\text { No. and } \% \text { of revision-orientated } \\
\text { comments leading to revision }\end{array}$} \\
\hline & & & 149 & $75 \%$ & 93 & $62 \%$ \\
\hline & Local & 231 & 223 & $97 \%$ & 179 & $80 \%$ \\
\hline & Subtotal & 429 & 372 & $87 \%$ & 272 & $73 \%$ \\
\hline \multirow[t]{3}{*}{ 2nd assignment } & Global & 183 & 136 & $74 \%$ & 79 & $58 \%$ \\
\hline & Local & 235 & 232 & $99 \%$ & 151 & $65 \%$ \\
\hline & Subtotal & 418 & 368 & $88 \%$ & 230 & $63 \%$ \\
\hline \multirow[t]{3}{*}{ 3rd assignment } & Global & 147 & 108 & $73 \%$ & 55 & $51 \%$ \\
\hline & Local & 176 & 167 & $95 \%$ & 118 & $71 \%$ \\
\hline & Subtotal & 323 & 275 & $85 \%$ & 173 & $63 \%$ \\
\hline
\end{tabular}

Adoption rate of revision-oriented comments $=$ No. of revision-oriented comments leading to actual revision/No. of revision-oriented comments

\subsubsection{Adoption Rate by Area}

Table 4 also shows that in all three rounds, student writers adopted significantly more local revision-oriented 
comments than global revision-oriented comments. In the first and third round, the adoption rates of local revision-oriented comments were nearly $20 \%$ higher than that of global ones $(80 \%$ vs $62 \%$ and $71 \%$ vs $51 \%)$. However, the results of previous studies were just opposite. In Ho's (2015) study, students adopted less local revision-oriented comments than global ones ( $60 \%$ vs $75 \%$ and $56 \%$ vs $59 \%$ in two CMC peer reviews). In Liu and Sadler's (2003) study, although students gave much more local revision-oriented comments than global ones, the adoption rate of local revision-oriented comments was still much lower than that of global ones $(22 \%$ vs $43 \%$ ). The high adoption rate of local revision-oriented comments in this study may indicate students' strong confidence in their peers' English proficiency. The students in this study major in International Business. When they were admitted into this programme, their English proficiency was an important criterion for consideration. Their average score of English in College Entrance Examination was 134 (the total was 150), approximately equivalent to IELTS 7.5. In questionnaire, $100 \%$ of students showed their trust in peers.

\subsection{Students' Perception of the CMC Peer Review Activities}

\subsubsection{Students' Perception of the Two-Step CMC Peer Review Process and Their Preference of Different Modes}

29 students finished the questionnaire survey at the end of the semester. The first seven questions in the survey were asking students about their feelings and opinion concerning the two-step CMC peer review (Word commenting followed by peer discussion via Zoom). Also, since they had done traditional two-step peer review (paper-based commenting followed by face-to-face classroom discussion) last semester, they were also asked about their preferences. Table 5 shows the results.

Table 5. Students' response to experiences of the CMC peer review

\begin{tabular}{|c|c|c|c|c|c|}
\hline \multirow[t]{2}{*}{ Statements } & \multicolumn{5}{|c|}{ Degree of agreement } \\
\hline & $\begin{array}{l}\text { Strongly } \\
\text { disagree }\end{array}$ & Disagree & Undecided & Agree & $\begin{array}{l}\text { Strongly } \\
\text { agree }\end{array}$ \\
\hline $\begin{array}{l}\text { 1. I enjoyed the electronic commenting mode (using "insert } \\
\text { comments" features of Word). }\end{array}$ & $4 \%$ & $0 \%$ & $10 \%$ & $41 \%$ & $45 \%$ \\
\hline $\begin{array}{l}\text { 2. The Word commenting features made it easy for me to } \\
\text { comment on my peers' writing. }\end{array}$ & $4 \%$ & $0 \%$ & $10 \%$ & $21 \%$ & $65 \%$ \\
\hline $\begin{array}{l}\text { 3. I prefer the Word commenting mode to the paper-based } \\
\text { commenting mode. }\end{array}$ & $4 \%$ & $7 \%$ & $10 \%$ & $24 \%$ & $55 \%$ \\
\hline 4. I enjoyed peer interaction via Zoom. & $0 \%$ & $10 \%$ & $14 \%$ & $48 \%$ & $28 \%$ \\
\hline $\begin{array}{l}\text { 5. Zoom made it easy for my peers and me to discuss our } \\
\text { writing and exchange ideas. }\end{array}$ & $0 \%$ & $10 \%$ & $14 \%$ & $52 \%$ & $24 \%$ \\
\hline $\begin{array}{l}\text { 6. I prefer having peer interaction via Zoom to peer interaction } \\
\text { in classroom. }\end{array}$ & $7 \%$ & $14 \%$ & $24 \%$ & $17 \%$ & $38 \%$ \\
\hline $\begin{array}{l}\text { 7. I would like to attend Word-and-Zoom-based peer review } \\
\text { activities again if I am given the opportunity in the future. }\end{array}$ & $4 \%$ & $10 \%$ & $21 \%$ & $31 \%$ & $34 \%$ \\
\hline
\end{tabular}

With respect to the first step of the peer review process, most students held positive attitude (both "agree" and "strongly agree"). $86 \%$ of students enjoyed the electronic commenting mode and agreed or strongly agree (65\%) that the Word commenting features made it easy for them to comment on peers' writing. When comparing the traditional commenting mode and the Word commenting mode, $79 \%$ said they preferred Word commenting.

In their reflective journals, students also expressed their recognition of the advantages of Word commenting, such as its convenience, clarity, neatness and the sense of professionalism. Specific views included:

- "Commenting with Word is very convenient. I can list my points clearly, which is good for discussion. And Word's built-in review feature made it easier to spot punctuation errors, grammar errors, and so on. It is better than writing comments on paper and I hope we can keep this mode."

- "The marginal comments on Word file helped me locate my mistakes more easily. Besides, we had to reply to the reviewer's comments this time. It's more professional and interesting."

- "I like commenting on computer. The essay with electronic comments looks very neat and formal. I felt a sense of fulfillment when I finished commenting on my partner's essay."

Some students expressed a mixed feeling, for instance:

- "I think using Word commenting is more efficient and convenient. The only bad thing is that my eyes easily felt tired after staring at screen for a long time. So, I had to stop and relax my eyes for a while. Sometimes my 
thoughts were interrupted."

A few students expressed the disadvantages of electronic commenting, mainly being time-and energy-consuming:

- "Commenting on computer is more difficult, because writing on paper is easier than typing. Also, I am not so familiar with Word's function. It took a longer time and more energy to use computer than use paper."

With respect to the second step, $76 \%$ of students enjoyed peer interaction via Zoom and agreed that Zoom made it easy for them to discuss their writing while $10 \%$ showed disagreement. But when comparing the traditional face-to-face discussion and the online discussion, only 55\% said they preferred Zoom discussion; while 21\% said they did not prefer this new mode and $24 \%$ remained undecided.

In their journals, students pointed out the advantages of Zoom discussion, such as its screen sharing function, its separate, private breakout rooms and the immediate real-time interaction. Specific positive views included:

- "It was easy to do discussion via Zoom because we could share screen and chat freely. This interaction promoted my understanding of my partner's comments."

- "I felt great. I like the atmosphere of learning together and have "debate" on specific questions. we can have a private discussion, a relatively personal time and space to discuss our comments without being disturbed by other students."

Some students' views were negative. They noticed the disadvantages of online Zoom discussion, such as lack of body language and facial expression. One student mentioned the problem of unstable network:

- "The most difficult problem I had to face was the unstable network which seriously disturbed our discussion on Zoom. My peer could not hear me from time to time, only to hear some electric sound. Our discussion was often interrupted by the failure of connection."

When asked whether they would like to attend Word-and-Zoom-based peer review activities again in the future, $65 \%$ expressed their willingness, while $14 \%$ showed their unwillingness and $21 \%$ remained undecided. Although most students were positive to Wording commenting (86\%) and Zoom discussion (76\%), they were somehow hesitant to choose this mode.

\subsubsection{Students' Perception of Effectiveness and Usefulness of the CMC Peer Review}

The second part of the questionnaire (questions 8 to 16) was asking students about their perception of effectiveness and usefulness of the CMC peer review. The results are shown in Table 6.

Table 6. Students' response to the effectiveness and the usefulness of CMC peer review

\begin{tabular}{|c|c|c|c|c|c|}
\hline \multirow[t]{2}{*}{ Statements } & \multicolumn{5}{|c|}{ Degree of agreement } \\
\hline & $\begin{array}{l}\text { Strongly } \\
\text { disagree }\end{array}$ & Disagree & Undecided & Agree & $\begin{array}{l}\text { Strongly } \\
\text { agree }\end{array}$ \\
\hline $\begin{array}{l}\text { 8. In the peer review activities, I received sufficient training from the } \\
\text { teacher. }\end{array}$ & $0 \%$ & $0 \%$ & $10 \%$ & $52 \%$ & $38 \%$ \\
\hline 9. Peer Review Forms were useful to guide me in giving comments. & $0 \%$ & $0 \%$ & $7 \%$ & $59 \%$ & $34 \%$ \\
\hline 10. I trusted my peer and I read their comments carefully. & $0 \%$ & $0 \%$ & $0 \%$ & $45 \%$ & $55 \%$ \\
\hline 11. Peer review activities were helpful in my text revision. & $0 \%$ & $0 \%$ & $0 \%$ & $52 \%$ & $48 \%$ \\
\hline $\begin{array}{l}\text { 12. Peer review activities helped me enrich the content of my } \\
\text { writing. }\end{array}$ & $0 \%$ & $0 \%$ & $21 \%$ & $38 \%$ & $41 \%$ \\
\hline $\begin{array}{l}\text { 13. Peer review activities helped me improve the organization of my } \\
\text { writing. }\end{array}$ & $0 \%$ & $0 \%$ & $17 \%$ & $48 \%$ & $35 \%$ \\
\hline $\begin{array}{l}\text { 14. Peer review activities helped me improve the language of my } \\
\text { writing. }\end{array}$ & $0 \%$ & $4 \%$ & $24 \%$ & $48 \%$ & $24 \%$ \\
\hline $\begin{array}{l}\text { 15. My commenting skills are improving and now I become more } \\
\text { confident in giving comments to my peer's writing. }\end{array}$ & $0 \%$ & $0 \%$ & $10 \%$ & $62 \%$ & $28 \%$ \\
\hline 16. Peer review activities are helpful in improving my writing ability. & $0 \%$ & $0 \%$ & $10 \%$ & $62 \%$ & $28 \%$ \\
\hline
\end{tabular}

When considering the review process, the majority of students were satisfied with teacher's training and Peer Review Form. The statistics show that $90 \%$ of students thought they had received sufficient training from the teacher and $93 \%$ considered Peer Review Forms useful to guide them in giving comments. Specific views in reflective journals included: 
- "The training was necessary and adequate. It gave me a very clear outline about what to do during the commenting and discussing parts."

- "The peer review form gives us a better understanding of what we need to pay attention to when commenting. The error table lists all kinds of possible problems, so that we can compare them when we read the articles of our peers."

- "Teacher's modeling is great. I seemed to do commenting on the sample essay with teacher together. Just following teacher's steps, I found many problems which I did not pay attention to before. I hope we can do this again in future classes."

When evaluating the usefulness of peer review, remarkably, all students $(100 \%)$ trusted their peer and all students agreed that $\mathrm{CMC}$ peer review activities were helpful in their text revision. The degree of usefulness in each specific area they perceived varied: $83 \%$ of students recognized the usefulness of peer reviews in improving organization; $79 \%$ agreed that peer reviews helped them enrich the content of their writing; $72 \%$ thought peer review helped them improve the language. These attitudes were also reflected in their journals, for instance:

- "I love this peer review so much because my partner is very serious and responsible."

- "The most helpful part is organization. My peer felt that my third and fourth arguments could be combined into one paragraph. After revision, I found it was much more concise and convincing."

- "She helps me most with my connection between sentences. She found my sentence confusing. And later we found out it was the lack of connection which led to the potential misunderstanding. So, I add some connection phrases."

- "My partner and I have different ways of thinking, so our writing styles vary a lot. She's good at creating a scenario and giving vivid details while I'm good at making summaries. The comments we gave are complementary. So, ideas development is the most helpful aspect."

- "Very helpful, my partner gave me a lot of help in language. He helps me to distinguish the phrases between "lead sb. to sth." and "lead to sth." and the word "enforce" and "force".,"

Sometimes even though students could not find out the problem and give detailed suggestion, through discussion, they still came up with a solution. Students recognized this good impact of meaning negotiation. For instance:

"I think some of her sentences are incoherent, but I couldn't tell which part is wrong. So, we discuss together and finally solve the problem."

Apart from positive views, a few students expected improvement of partner's commenting skills, for instance:

- "I think my peer's commenting skills are great, especially in grammar. But her skills are not very comprehensive enough. I hope she can pay attention on my organization, because I am weak in this aspect.

The survey results also show that at the end of the semester, $90 \%$ of students perceived improvement in their commenting skills and became more confident in giving comments. In terms of the long-term impact of peer review, the results are also very positive: $90 \%$ thought that Peer review activities are helpful in improving their writing ability. The long-term benefits mentioned in students' reflective journals included most of benefits reported in the peer review literature: a better understanding of good writing, development of a sense of audience, critical thinking, consolidation of language knowledge and a habit of self-regulatory behaviours, etc. Specific views included:

- "Peer review gives me a better understanding of the criteria of a good essay. Consequently, I pay more attention to these criteria when I write next time."

- "I like to read my peer's writing. To my surprise, some of my peer's opinions are quite different from mine. Reading her writing gave me another perspective on the same topic. I learn different writing styles and skills through comparing her essay and mine."

- "It appears that the ideas contained in our words are not as clear as we thought they would be when we wrote them, as least not for the readers. We seemingly tend to be more subjective than we think. Therefore, it's essential for us to use certain writing techniques we learnt from the class. For instance, as a reviewer, I discovered that using conjunction would definitely make a paragraph easier to read, but I did not realize this before no matter how many times the teacher had emphasized the importance of conjunctions. However, once I experienced the difference that a conjunction could make to the structure of a paragraph, this part of knowledge was activated and would not fade easily."

- "A kind of critical thinking has been fostered along the way. I gradually tend to reflect on the words I read 
instead of simply accept them. Also, self-reflection will occur in my own writing."

- "After review activities, my partner and I would try to verify some confusing points. We did dictionary work and searched all over the Internet. Many of our confusions were untangled and the knowledge was consolidated."

- "I would check my own writing to see whether there were some problems listed in review form before giving it to my peer so that I would not feel embarrassed when my errors were picked up by my peer, especially those simple errors."

\section{Conclusion}

This study aims to investigate the effects of the two-step CMC peer review process (Word commenting followed by Zoom discussion) in English writing courses for EFL learners, and students' perceptions of this mode. The findings are encouraging.

Firstly, the proportions of revision-oriented comments in three rounds of CMC peer review activities remained at a high level of above $85 \%$. Secondly, students gave relatively balanced comments. Although they gave more local comments probably due to Word's automatic check of spelling and grammar, the ratio of revision-oriented comments in global areas to revision-oriented comments in local areas was more balanced ( $40 \% \mathrm{vs} 60 \%$ ), compared with Liou and Saddle's results. Even though global revision-oriented comments were less than local ones, students did not overlook the global issues. They gave second biggest proportion of revision-oriented comments in content. Also, more students considered peer comments useful in improving their global issues than local issues. Thirdly, the adoption rates of revision-oriented comments were also at a high level $(63 \%-73 \%)$ compared with those reported in previous studies. Fourthly, most students held positive attitudes toward this two-step CMC peer review and perceived this new mode useful in their text revision and development of writing ability. $65 \%$ of them expressed their willingness to attend this mode of review activities in the future.

The favorable results can be explained by two reasons. Firstly, the speech-based online Zoom discussion seemed more efficient than text-based communication tools such as MSN, Blackboard and MOO because students did not need to type on screen. In the private breakout rooms, students could see each other and shared documents when talking. This greatly promoted their communication and subsequent adoption of comments. In their study, Ho and Savignon (2007) argued that lack of oral discussion was "most common drawback" for CMC peer review and that was why most students preferred face-to-face peer review. Zoom discussion can overcome this drawback. Secondly, the students had gained experiences of peer review in the previous semester, so they were familiar with the process and their collaboration with classmates was smooth.

However, there are some unfavorable results. The major one is that the number of comments students gave in the last round of peer review activity decreased dramatically. In his one-year longitudinal study on Chinese undergraduate EFL students, Wang (2014) discovered that students' perceived usefulness of peer feedback decreased over time. This study partly coincides with Wang's results that students' enthusiasm for peer review decreased over time because of the boredom of the same task pattern. The heavy workload of electronic commenting mode and long-time online classes of this semester exacerbated the situation and the students expressed their tiredness near the end of semester. This tiredness may explain why, in the end-of-semester questionnaire, students were reluctant to choose CMC peer review in the future even though most of them recognized its advantages and usefulness.

Another problem is lack of teacher's interference during Zoom discussion. In the previous semester, while students conducted face-to-face classroom discussion, the teacher could observe in a distance and interfere when necessary and students could ask for help at any time. In Zoom discussion, however, students discussed in separate breakout rooms. The teacher could join each room, but I did not do that in order not to disturb them. In their first reflective journal, some students mentioned that they did not know what to do when they could not reach an agreement in discussion. In the second and third rounds, I made some adjustments by telling students that they could invite me to join them when needed or they could make an appointment with me after class. But only two groups invited me and no group took the opportunities of outside-class teacher-student conference as they might not want to bother. On the whole, the teacher's interference was not immediate and sufficient enough. Further research is needed to explore how teacher can interfere and provide adequate support in this context.

The results of this study shed light on the future EFL writing class. Firstly, it reveals that despite some negative results, the two-step CMC peer review process with Word commenting followed by discussion via online video conferencing system can be used as a useful tool in EFL writing class. Secondly, workload needs to be taken into consideration. When students show tiredness, the teacher needs to make some adjustments, for instance, 
reducing the times of review activity or change certain pattern to achieve the balanced use of traditional mode and CMC mode just as Ho (2015) also suggested. Thirdly, more interference is needed in discussion session.

Due to the small number of participants, this study has some limitations. What's more, in the second step of peer review, students' discussions in each breakout rooms were not recorded to analyze their turns and discourses. Thus, Future study could include more students. Researcher can also track students' performance in discussion to find out how online video conferencing system can facilitate peer review activities.

\section{References}

Berg, E. (1999). The effects of trained peer response on ESL students' revision types and writing quality. Journal of Second Language Writing, 8(3), 215-241. https://doi.org/10.1016/S1060-3743(99)80115-5

Chang, C. (2012). Peer Review via Three Modes in an EFL Writing Course. Computers and Composition, 29(1), 63-78. https://doi.org/10.1016/j.compcom.2012.01.001

Chen, K. (2012). Blog-Based Peer Reviewing in EFL Writing Classrooms for Chinese Speakers. Computers and Composition, 29(4), 280-291. https://doi.org/10.1016/j.compcom.2012.09.004

Guardado, M., \& Shi, L. (2007). ESL students' experiences of online peer feedback. Computers and Composition, 24(4), 443-461. https://doi.org/10.1016/j.compcom.2007.03.002

Ho, M. (2015). The Effects of Face-to-Face and Computer-Mediated Peer Review on EFL Writers' Comments and Revisions. Australasian Journal of Educational Technology, 31(1), 1-15. https://doi.org/10.14742/ajet.495

Ho, M., \& Savignon, S. (2007). Face-to-face and Computer-mediated Peer Review in EFL Writing. CALICO Journal, 24(2), 269-290. https://doi.org/10.1558/cj.v24i2.269-290

James, C. (2001). Errors in language learning and use: Exploring error analysis. Beijing: Foreign Language Teaching and Research Press.

Jin, L., \& Zhu, W. (2010). Dynamic Motives in ESL Computer-Mediated Peer Response. Computers and Composition, 27(4), 284-303. https://doi.org/10.1016/j.compcom.2010.09.001

Liou, H., \& Peng, Z. (2009). Training effects on computer-mediated peer review. System (Linköping), 37(3), 514-525. https://doi.org/10.1016/j.system.2009.01.005

Liu, J., \& Sadler, R. (2003). The effect and affect of peer review in electronic versus traditional modes on L2 writing. Journal of English for Academic Purposes, 2(3), 193-227. https://doi.org/10.1016/S1475-1585(03)00025-0

Mendonça, C., \& Johnson, K. (1994). Peer Review Negotiations: Revision Activities in ESL Writing Instruction. TESOL Quarterly, 28(4), 745-769. https://doi.org/10.2307/3587558

Min, H. (2005). Training students to become successful peer reviewers. System (Linköping), 33(2), 293-308. https://doi.org/10.1016/j.system.2004.11.003

Min, H. (2006). The effects of trained peer review on EFL students' revision types and writing quality. Journal of Second Language Writing, 15(2), 118-141. https://doi.org/10.1016/j.jslw.2006.01.003

Mohamad, Y. A., Supyan, H., \& Mohanaad, S. (2018). The Effect of Peers' and Teacher's E-Feedback on Writing Anxiety Level Through CMC Applications. International Journal of Emerging Technologies in Learning, 13(11), 196-207. https://doi.org/10.3991/ijet.v13i11.8448

Paulus, T. (1999). The effect of peer and teacher feedback on student writing. Journal of Second Language Writing, 8(3), 265-289. https://doi.org/10.1016/S1060-3743(99)80117-9

Pritchard, R., \& Morrow, D. (2017). Comparison of Online and Face-to-Face Peer Review of Writing. Computers and Composition, 46, 87-103. https://doi.org/10.1016/j.compcom.2017.09.006

Rollinson, P. (2005). Using peer feedback in the ESL writing class. ELT Journal, 59(1), 23-30. https://doi.org/10.1093/elt/cci003

Shen, B., Bai, B., \& Xue, W. (2020). The effects of peer assessment on learner autonomy: An empirical study in a Chinese college English writing class. Studies in Educational Evaluation, 64. https://doi.org/10.1016/j.stueduc.2019.100821

Tsui, A., \& Ng, M. (2000). Do Secondary L2 Writers Benefit from Peer Comments? Journal of Second Language Writing, 9(2), 147-170. https://doi.org/10.1016/S1060-3743(00)00022-9 
Villamil, O., \& De Guerrero, M. (1998). Assessing the Impact of Peer Revision on L2 Writing. Applied Linguistics, 19(4), 491-514. https://doi.org/10.1093/applin/19.4.491

Wang, W. (2014). Students' perceptions of rubric-referenced peer feedback on EFL writing: A longitudinal inquiry. Assessing Writing, 19, 80-96. https://doi.org/10.1016/j.asw.2013.11.008

Wu, W., Petit, E., \& Chen, C. (2015). EFL writing revision with blind expert and peer review using a CMC open forum. Computer Assisted Language Learning, 28(1), 58-80. https://doi.org/10.1080/09588221.2014.937442

Xu, Q., \& Yu, S. (2018). An Action Research on Computer-Mediated Communication (CMC) Peer Feedback in EFL Writing Context. The Asia-Pacific Education Researcher, 27(3), 207-216. https://doi.org/10.1007/s40299-018-0379-0

Yang, M., Richard, B., \& Zhen, Y. (2006). A Comparative Study of Peer and Teacher Feedback in a Chinese EFL Writing Class. Journal of Second Language Writing, 15(3), 179-200. https://doi.org/10.1016/j.jslw.2006.09.004

Yu, H.-J., \& Choe, H. S. (2010). The Effects of Online Peer Feedback with TrackChanges and Synchronous Computer-Mediated Communication. English Language and Literature, 23(2), 197-214. https://doi.org/10.35771/engdoi.2010.23.2.010

\section{Appendix A}

\section{Peer Review Form for A Comparison Essay}

\section{Author's name: __ Reviewer's name:}

The aim of this peer review is to provide your peer with honest but helpful responses as the reader of this essay. Read the essay before next Tuesday and respond to these questions as completely as possible.

What do you like best about this essay? In what aspect has the writer done a good job? Give your praise whenever possible.

\section{CONTENTS}

1) Can you find a thesis statement in introduction? If yes, underline it in the essay. If not, suggest the writer to write one.

2) Is the thesis statement clear? If not, explain why not (for example, it does not show the writer's opinion on the topic or does not state whether the writer is going to focus on similarities or differences, etc.) and give suggestion to improve.

3) Does each body paragraph have a topic sentence? If yes, underline it. If not, suggest the writer to write a TS.

4) How many reasons (TSs) are provided to support the thesis? Do all these reasons logically support the thesis? If not, explain why not and try to give suggestions to improve.

5) Within each paragraph, of the reasons or evidences given to support the TS, which one/ones is/are irrelevant or illogical? Point it/them out and explain your reasons and if you can, suggest improvements.

6) What part(s) should be developed more? Explain why and make some suggestions for improvement.

7) What part(s) are confusing? Explain why and make some suggestions for improvement.

\section{ORGANIZATIONS}

8) Does the essay contain "introduction", "body" and "conclusion"? If not, suggest the writer to add the missing part. Is the introduction effective one? Is the conclusion effective one? If not, explain why and suggest improvement.

9) Which pattern (block pattern or point-to-point pattern) does the writer use to make the comparison or contrast? Is the pattern clear? Did the writer use transition devices to link paragraphs? If not, explain why not and suggest improvements.

10) Are the sentences in each paragraph logically connected? If not, explain why not and suggest improvements.

11) Identify vocabulary errors and language problems with the Error Type Chart

\section{VOCABULARY}

Vocabulary error Article error 
e.g., I saw many students standing in front of library.

\section{Part of speech error}

e.g., To summary, governments should take some measures to tackle the problem.

\section{Word formation error}

e.g., The dog is shock by her voice.

\section{Word choice error}

e.g., Library is much more conductive to studying.

\section{Collocation error}

e.g., He is good in playing basketball.

\section{Pronoun error}

e.g., But on the other hand, a child may be spoiled by their parents.

\section{Wordiness or repetitive use of word}

e.g., After a survey concerning about why many freshmen fail to persist in reading extensively, I can find four reasons.

\section{LANGUAGE USE}

\section{Grammar error}

Tense error

e.g., Maybe I can find a better job when I went into society.

\section{Agreement errors}

e.g., He never lose heart; he always stay positive.

Voice error

e.g., They traveled with their own cameras which used to memorize their happy time.

\section{Sentence structure error}

e.g., All I wanted to say or do which I can't remember now.

\section{Sentence fragment}

e.g., I won't leave the house. Until I hear from you.

\section{run-on sentence}

e.g., I'm a woman I am a truck driver.

\section{MECHANICS}

\section{Mechanics error Spelling error}

\section{Capitalization error}

\section{Punctuation error}

On next Tuesday you will discuss the ideas in this essay with your partner. Be sure to discuss specific ways in which the essay can be improved. Remember, you are reading and discussing how well the IDEAS are presented-DO NOT spend too much time talking about the GRAMMAR.

\section{Copyrights}

Copyright for this article is retained by the author, with first publication rights granted to the journal.

This is an open-access article distributed under the terms and conditions of the Creative Commons Attribution license (http://creativecommons.org/licenses/by/4.0/). 